\title{
ORIGEM DA VIDA: COMO LICENCIANDOS EM CIÊNCIAS BIOLÓGICAS LIDAM COM ESTE TEMA?
}

\author{
Life's origin: how do pre-service Biology teachers \\ deal with this subject?
}

\author{
Livia Baptista Nicolini ${ }^{1}$ \\ Eliane Brígida Morais Falcão ${ }^{2}$ \\ Flavio Silva Faria ${ }^{3}$
}

Resumo: A presente pesquisa identificou e analisou a representação social do tema origem da vida entre estudantes da licenciatura em Ciências Biológicas de uma universidade federal do Rio de Janeiro. A coleta de dados foi realizada por meio de questionário, e seus resultados analisados qualitativamente, de acordo com a metodologia do Discurso do Sujeito Coletivo (DSC). A análise e discussão dos resultados permitiram concluir que a representação social dos licenciandos, em relação ao tema proposto, apresenta elementos de uma cultura religiosa e de uma cultura científica. A análise dos elementos científicos nos permitiu identificar algumas deficiências nos conhecimentos expressos por esses sujeitos; apresentamos indícios de que essas deficiências derivam basicamente de duas fontes: (a) a ausência de abordagem específica do tema no curso de graduação da universidade pesquisada e (b) o conteúdo dos livros didáticos do Ensino Médio.

Palavras-chave: Origem da vida. Formação inicial de professores de Biologia. Ciências biológicas. Crenças religiosas. Ensino de ciências.

\begin{abstract}
This research identified and analyzed social representations about the life origin among preservice Biology teachers from a Rio de Janeiro federal university. Data were collected through questionnaires and the outcomes were analyzed in a qualitatively basis, according to the Collective Subject Discourse (CSD) approach. Data analysis and discussion allowed concluding that pre-service social representations about this subject, shows elements of a religious culture and the scientific ones. The scientific elements' analysis allowed identifying some deficiencies in the knowledge expressed by them; the outcomes provided evidences that those deficiencies come from two main sources: (a) lack of a approach to the origin of life subject, while in the undergraduate program; and (b) High School didactic books contents.
\end{abstract}

Keywords: Life's origin. Pre-service Biology teachers' education. Biological sciences. Religious beliefs. Science teaching.

\footnotetext{
${ }^{1}$ Licenciatura e Bacharelado em Ciências Biológicas, mestre em Tecnologia Educacional nas Ciências da Saúde. Professora de Ciências e Biologia do Ensino Fundamental e Médio. Rio de Janeiro, RJ, Brasil.

${ }^{2}$ Bacharelado em Psicologia, doutora em Ciências. Docente, Núcleo de Tecnologia Educacional para a Saúde, Universidade Federal do Rio de Janeiro (NUTES/UFRJ). Rio de Janeiro, RJ, Brasil. < elianebrigida@uol.com.br>

${ }^{3}$ Bacharelado em Ciências Biológicas, doutor em Biofísica. Docente, Departamento de Genética, Instituto de Biologia, UFRJ. Rio de Janeiro, RJ, Brasil. <flavio@biologia.ufrj.br>

${ }^{1}$ Rua Conde de Bonfim, 429/202

Tijuca - Rio de Janeiro, RJ

$20.520-051$ 
Nicolini, L. B.; Falcão, E. B. M.; Faria, F. S.

\section{Introdução}

Os estudos sobre origem da vida constituem um campo de investigação científica e um tema de ensino escolar, transmitido na universidade e em escolas de nível fundamental e médio. Um problema que habitualmente atinge o ensino dessa disciplina é a notória pluralidade de teorias e abordagens com que se defronta qualquer um que examine o assunto, a sua transdisciplinaridade, e a falta de capacitação dos professores para o ensino deste assunto. Apesar dessa dificuldade, convém esclarecer que, em certa medida, essa pluralidade de abordagens repousa sobre um fundo comum, ou consensual, de pressupostos básicos, acatado pelos cientistas interessados nas ciências biológicas. São elementos dessa visão em comum neste campo do conhecimento científico: (1) a possibilidade de existência de vida em diferentes pontos do universo, uma vez que moléculas orgânicas simples não parecem ser exclusividade do planeta Terra; (2) a hipótese de que a evolução química teria sua base na conjunção de uma série de eventos abiogenéticos, que teriam dado origem às primeiras moléculas orgânicas simples e, nesse contexto, (3) a formação de grande quantidade de moléculas orgânicas simples e dos primeiros polímeros pode ter tido mais de uma origem em função dos intensos bombardeios de radiação que a Terra sofria (VIEYRA e SOUZA-BARROS, 2000; ZAIA, 2003; PERETÓ, 2005; DAMINELI e DAMINELI, 2007).

Além desses enunciados básicos, o consenso tende a abranger também a definição de pontos críticos de investigação experimental e teorização. Exemplo típico é o da tentativa de entender como foi possível estabelecer-se o tipo de relação que existe, nos seres vivos que conhecemos, entre o metabolismo celular e os sistemas informacionais baseados em ácidos nucléicos; este problema inclui também a relação entre diferentes tipos de ácidos nucléicos (RNA e DNA). Porém, conforme argumentamos anteriormente, desse pano de fundo comum emergem orientações de pesquisa extremamente diversas e, frequentemente, conflitantes (VIEYRA e SOUZA-BARROS, 2000; ZAIA, 2003; PERETÓ, 2005; DAMINELI e DAMINELI, 2007).

Há um outro aspecto do problema, referente ao tipo de conhecimento científico que está em jogo nos estudos sobre origem da vida. Aqui é importante estabelecer uma distinção entre (a) ciência em condições de encerramento (fechamento) e (b) ciência em condições abertas (BHASKAR, 1975) ${ }^{4}$. No primeiro caso, o objeto da investigação científica consiste de entidades e estruturas básicas do mundo físico (e que são diferentes em diferentes ciências da natureza, como a química, a biologia etc.); o cientista pode isolar esses objetos de investigação - e essa seria a função dos experimentos de laboratório - de interferências externas, de modo a determinar o modo como entidades básicas influenciam ou originam processos e eventos no mundo real. No segundo caso, estudam-se estruturas que estão além do controle experimental, mas cuja explicação depende do conhecimento adequado de uma série de estruturas e

\footnotetext{
${ }^{4}$ Dentre muitos autores atuantes em filosofia da ciência, as idéias de Bhaskar atraíram a nossa atenção, na medida em que põe em relevo uma série de nuanças educacionais e formativas que devem ser levadas em conta no âmbito das ciências naturais.
} 
processos, em geral elucidados pela ciência em condições de fechamento. Em princípio, essa distinção não é típica de disciplinas científicas inteiras; é de se esperar que, em cada campo do saber, estudos dos dois tipos serão possíveis e/ou necessários. No entanto, é seguro afirmar que, nas ciências da vida, a condição aberta será encontrada no estudo de estruturas de grande alcance geográfico, como na Ecologia, ainda mais quando acrescentamos uma dimensão temporal de longo prazo, como na Biologia Evolutiva.

Não é difícil concluir que a ciência em condições abertas impõe exigências especiais aos seus praticantes e estudantes, como, por exemplo, uma particular flexibilidade de julgamento e uma especial capacidade de integrar conhecimentos de tipos muito diferentes. Além disso, a ênfase na "previsão" dificilmente pode ser aí decisiva (ela não é excluída, mas ganha preeminência a ideia de que o mais fundamental na ciência é tornar algo inteligível, não fazer previsões). Devemos admitir que filósofos da ciência influenciados pela tradição empirista provavelmente questionariam esta interpretação. Conquanto exista aí um ponto importante de debate teórico, gostaríamos de chamar a atenção para a ocorrência, nos meios em que se exerce a atividade e a educação científicas, de uma discussão recorrente sobre: (a) "ciência aplicada" e "ciência pura" e (b) relação entre "modelo" e "realidade"; ora, a abordagem realista que acolhemos no presente trabalho tem justamente a virtude de mapear a origem de tais debates na própria natureza fundamental do empreendimento científico.

Pode-se, então, sugerir que a investigação e a aprendizagem do assunto "origem da vida" trazem exatamente essas exigências epistemológicas e de formação; e, também, que se as confundirmos com aquelas adequadas às condições de fechamento, o nosso tema de ensino será abordado de maneira distorcida (por mais diversas que sejam as informações a que os estudantes de graduação em geral têm acesso), uma vez que não serão apresentados fundamentais elementos para a compreensão do fenômeno (origem da vida) estudado ${ }^{5}$.

Com este breve sumário, apresentamos um dos aspectos que cercam a temática do trabalho, aqui relatado, referente à riqueza de conteúdos do tema "origem da vida" como um desafio ao ensino de ciências ao nível médio de escolaridade e em cursos de formação de professores de ciências naturais.

Como nossa pesquisa tem o ensino da origem da vida como foco, julgamos ser necessária a inclusão, em nossa discussão, de resultados de análise de livros didáticos ${ }^{6}$ do Ensino Médio. Nestes livros, os conceitos são apresentados, mas não aparecem as divergências e os problemas que estes conceitos ainda apresentam. Na realidade, eles não captam a diversidade de ideias no campo de pesquisa em questão. É interessante notar que uma situação semelhante

\footnotetext{
${ }^{5}$ Scheid, Ferrari e Delizoicov (2005), em artigo que relaciona questões epistemológicas e dificuldades do ensino de ciências, observaram que "possivelmente, um dos entraves no processo ensino-aprendizagem está na visão positivista de ciência, ainda muito presente, que impõe uma racionalidade técnica que torna o professor responsável pela detenção de verdades descobertas, que transmite aos seus alunos como prontas, acabadas, inquestionáveis" (p. 224).

${ }^{6}$ Esta análise está descrita em Nicolini (2006), e os livros pesquisados foram: Amabis e Martho (1995); César e Sezar (1995); Linhares e Gewandsznajder (1995); Soares (1995); Lopes (1997); Linhares e Gewandsznajder (1998); Linhares e Gewandsznajder (2000); César e Sezar (2002a); César e Sezar (2002b); Linhares e Gewandsznajder (2003); Amabis e Martho (2004).
} 
foi detectada no caso dos estudos sobre o conceito de ser vivo, ou definição de vida. Kawasaki e El-Hani (2002) analisaram as definições de vida encontradas em livros didáticos do Ensino Médio $^{7}$ e constataram que nenhum deles apresentou ideias que demonstram as divergências no meio científico. Preocupados com os textos escolares que chegam às salas de aulas, Bizzo e Molina (2004) abordaram distorções de conceitos centrais do darwinismo. Na perspectiva desses resultados, não é difícil concluir que questões tais como 'origem da vida', 'definição de vida', 'evolução e darwinismo' são relevantes para a formação científica, humana e social, e merecem, por isso mesmo, especial atenção nos contextos educacionais.

Considerando as características científicas de conteúdo do tema em questão, os resultados da análise de livros didáticos e as exigências oficiais do ensino do assunto origem da vida nos Ensinos Fundamental e Médio ${ }^{8}$ (BRASIL, 2006), buscou-se, na pesquisa aqui relatada, investigar as concepções de origem da vida de licenciandos - futuros professores de ciências e biologia - de um importante curso de graduação de uma universidade federal do Rio de Janeiro. Duas justificativas sustentaram tal decisão: o tema origem da vida está previsto nos currículos escolares tanto do Ensino Fundamental quanto de Ensino Médio; e a observação de que o tema origem da vida é objeto, com alguma frequência, de relatos de dificuldades de ensino. Com base nos resultados, tentaremos compreender, identificar e melhor caracterizar dificuldades e possibilidades para a melhoria do ensino de "origem da vida".

\section{Objetivo e metodologia}

Considerando o exposto na introdução, partimos do pressuposto de que, possivelmente, seriam diversificados os conteúdos explicativos do tema origem da vida entre os licenciandos. Para distinguir os elementos básicos da diversidade de explicações, optamos por fazer uso do conceito de representação social e da metodologia do Discurso do Sujeito Coletivo (DSC).

O conceito de representação social "toma como ponto de partida, a diversidade dos indivíduos, atitudes e fenômenos, em toda sua estranheza e imprevisibilidade. Seu objetivo é descobrir como os indivíduos e grupos podem construir um mundo estável, previsível, a partir de tal diversidade" (MOSCOVICI, 2003, p. 79).

\footnotetext{
${ }^{7}$ Os livros analisados por Kawasaki e El-Hani (2002) foram: Amabis e Martho, (1997); César e Sezar, (1998); Laurence, (2000); Lopes, (1999); Marczwski e Vélez, (1999); Morandine e Bellinello, (1999); Paulino, (2000); Soares, (1999).

${ }^{8}$ Os Parâmetros Curriculares Nacionais para o Ensino Médio (BRASIL, 2006) apresentam os eixos temáticos dos conteúdos de biologia: Interação entre os seres vivos; Qualidade de vida das populações humanas; Identidade dos seres vivos; Diversidade da vida; Ecologia; Transmissão da vida, ética e manipulação gênica; Origem e evolução da vida.

${ }^{9}$ A convivência dos autores com estudantes licenciandos e professores da graduação em Ciências Biológicas registram diferentes depoimentos a respeito.
} 
Origem da vida: como licenciandos ...

A representação social dos sujeitos foi identificada e analisada de forma qualitativa, a partir da metodologia do Discurso do Sujeito Coletivo (DSC) (LEFÈVRE e LEFĖVRE, 2003). Esta metodologia baseia-se na ideia de que indivíduos de um mesmo grupo possuem discursos semelhantes em relação a objetos comuns (temas ou questões de interesse comum), uma vez que interagem socialmente vinculados a tais objetos. Sistemas de crenças, valores e ações em um contexto social típico podem ser identificados em relação a tais objetos - a isto também podemos chamar de representação social. A metodologia do DSC, por meio de passos metodicamente estabelecidos, pretende identificar representações sociais.

Para entender a ideia do DSC, é preciso estar claro que o discurso é a fala do grupo no qual o sujeito se encontra. A justificativa, nas próprias palavras dos autores, é que "quando uma pessoa ou uma coletividade tem um pensamento sobre um dado tema, está-se dizendo que ela professa, ou adota, ou usa um ou vários discursos sobre o tema" (LEFÈVRE e LEFÈVRE, 2003, p. 14). O conjunto desses discursos é a representação social do tema em questão. O DSC é o conjunto de tais discursos, ou seja, é a representação social do tema, ou objeto, pesquisado. Para que os discursos sejam identificados, são destacadas as expressõeschave $(\mathrm{ECH})$ de cada resposta (ou depoimento) dos sujeitos investigados. Conjuntos de expressões-chaves semelhantes são reorganizados em torno de uma ideia-central (IC), que sintetiza o sentido básico de tais expressões. As ECH em conjunto formarão um discurso-síntese sobre o tema em questão, e a IC nomeará este discurso. Ademais, é possível encontrar-se uma ou mais IC e, portanto, um ou mais discursos-síntese, no grupo estudado. Estes discursosíntese reconstroem, "com pedaços de discursos individuais, como em um quebra-cabeça, tantos discursos-síntese quanto se julgue necessários para expressar uma dada "figura", ou seja, um dado pensar ou representação social sobre um fenômeno" (LEFÈVRE e LEFÈVRE, 2003 , p. 19). Esses passos foram seguidos para a identificação da representação social do grupo de licenciandos em relação ao tema proposto: origem da vida.

A investigação dos conteúdos que cercariam o tema origem da vida entre licenciandos - explicações, valores, imagens - fez uso de um questionário estruturado, mas sem comprometer a expressão livre dos sujeitos da pesquisa que também garantiu o seu anonimato. $\mathrm{O}$ questionário foi aplicado a 39 licenciandos e permitiu, além da obtenção de respostas em relação à origem da vida, a obtenção de dados que caracterizaram o perfil das crenças religiosas do grupo. Demos destaque a esse aspecto do pensamento dos sujeitos porque, por um lado, os religiosos e as instituições religiosas não são indiferentes ao tema origem da vida. Por outro lado, as ideias religiosas devem ser levadas em conta na caracterização do mundo cultural dos sujeitos.

Para a caracterização da representação social sobre o tema origem da vida foi feita a pergunta: como o licenciando explicava o surgimento do primeiro ser vivo na Terra?

Para a caracterização das crenças religiosas, foram elaboradas perguntas sobre o licenciando possuir ou não uma religião e, em caso afirmativo, qual seria esta; se o licenciando, no caso de possuir alguma religião, frequentava algum culto religioso e com que frequência; e se acreditava em Deus. Consideramos importante incluir questões a este respeito, pois o tema origem da vida apresenta formulações religiosas e estas poderiam ser usadas pelos licenciandos na resposta à questão central deste trabalho, o que auxiliaria o trabalho da interpretação dos resultados. 


\section{Resultados e discussão}

O grupo investigado foi o de estudantes da licenciatura em Ciências Biológicas de uma universidade pública localizada no Rio de Janeiro. Esta universidade é reconhecida no Brasil por suas qualidades de ensino e pesquisa e tais características referem-se também à unidade que oferece a formação de biólogos e licenciatura em Ciências Biológicas, aliando um conjunto de disciplinas teóricas e atuação na pesquisa.

Este curso está estruturado a partir dos temas principais da Biologia. Em consulta realizada na página do curso de Ciência Biológicas dessa universidade é possível perceber que o tema origem da vida não está previsto na ementa de nenhuma disciplina, obrigatória ou eletiva, do ciclo básico ou nos desdobramentos curriculares das seis modalidades possíveis de se cursar.

\section{Representação social de origem da vida: os discursos do sujeito coletivo}

A pergunta central deste trabalho - Como você explica o surgimento da vida na Terra pela primeira vez? - permitiu a identificação e caracterização de uma representação social que inclui a presença de três ideias centrais: (1) Origem no Big Bang; (2) Criação divina; e (3) Evolução química. $\mathrm{O}$ discurso Origem no Big Bang incluiu as expressões-chave relacionadas à origem do universo através de uma explosão inicial. O discurso Criação divina apresentou Deus como controlador dos eventos que originaram a Terra e o primeiro ser vivo. O discurso Evolução química incluiu as expressões-chave relacionadas a sequências de eventos que teriam ocorrido sob a influência da atmosfera primitiva; incluem-se aí desde interações entre moléculas inorgânicas até a formação do primeiro ser vivo. Cada licenciando só apresentou uma ideia central em sua resposta, que foi religiosa ou científica. O Quadro I apresenta os três DSC.

No discurso Origem no Big Bang não há nenhuma referência em relação à origem da Terra e nem explicita o surgimento da vida na mesma; confunde a origem da vida com a origem do universo, reunindo dados e informações sobre eventos que teriam ocorrido em momentos e formas distintos. Esse discurso mostra indícios de dificuldades básicas no campo das explicações científicas do tema.

O discurso Criação divina ${ }^{10}$ expressa a concepção religiosa da origem da vida. Embora a maioria dos licenciandos possua crenças religiosas, ligadas ou não a uma religião ${ }^{11}$, este

\footnotetext{
${ }^{10}$ Os seis alunos com concepções religiosas sobre a origem da vida (DSC 2) distribuíram-se da seguinte forma: Evangélicos, dois; Católicos, dois; Espírita, um; Sem religião, um.

${ }^{11}$ Os licenciandos adeptos de uma religião distribuíram-se da seguinte forma: Católica, 15 alunos; Evangélica, quatro; Espírita, cinco; e Budista, um. Dos demais 14 alunos, 13 indicaram não possuir religião e houve um que não respondeu. Mas, apesar de 13 alunos não terem alegado participar de qualquer religião, sete deles disseram acreditar em Deus (mesmo sem aderir a uma religião); cinco declararam-se em dúvida, e apenas um aluno declarou-se ateu.
} 
Origem da vida: como licenciandos ...

Quadro 1. Os Discursos do Sujeito Coletivo (DSC).

\begin{tabular}{|c|c|}
\hline Ideias centrais & DSC \\
\hline Origem no Big Bang (DSC 1) & $\begin{array}{l}\text { "Teoria do Big Bang. As transformações e condições surgidas no universo } \\
\text { durante a formação dos planetas. As explosões a partir do choque entre diver- } \\
\text { sas partículas, formando uma nebulosa onde as partículas se condensaram } \\
\text { sendo atraídas para o centro mais denso da galáxia que é o sol." }\end{array}$ \\
\hline Criação divina (DSC 2) & $\begin{array}{l}\text { "O surgimento da vida na Terra ocorreu pelo Criacionismo ou Criação Divina } \\
\text { dos primeiros seres vivos através da Força e Ação Divina. Foram criados por } \\
\text { Deus devido a leis naturais criadas por Ele." }\end{array}$ \\
\hline Evolução química (DSC 3) & $\begin{array}{l}\text { "Um acontecimento ao acaso permitiu a união de certos elementos químicos } \\
\text { formando as moléculas orgânicas. A vida surge espontaneamente em qualquer } \\
\text { parte do universo através do aumento da complexidade de estruturas não vivas } \\
\text { e a combinação de diversos fatores e eventos químicos, físicos e biológicos, } \\
\text { que juntos com as condições ambientais propícias originou a vida. A sucessão } \\
\text { de eventos complementares, como o de substâncias químicas se combinaram } \\
\text { e começaram a se organizar e criar complexidade. A origem da vida, assim, } \\
\text { pode ser explicada pela teoria da formação do coacervato: tese da sopa orgâni- } \\
\text { ca ou caldo primordial. Dadas as condições da Terra e oceanos primordiais, a } \\
\text { vida torna-se inevitável ao longo de bilhões de anos. A Terra possuía caracterís- } \\
\text { ticas únicas que permitiram a complexidade de moléculas simples pela incidên- } \\
\text { cia de grande quantidade de energia sobre determinadas partículas e a atração } \\
\text { química de substâncias e elementos químicos presentes na atmosfera, sendo } \\
\text { que a interação entre componentes desta, possibilitou o surgimento dos primei- } \\
\text { ros organismos. A atmosfera era composta e repleta de gases ou moléculas } \\
\text { como metano, água, amônia e gás carbônico, num período de intensa atividade } \\
\text { vulcânica. Houve chuva que resfriou a superfície da Terra e com ela vieram os } \\
\text { gases que foram rearranjados por descargas elétricas e reações químicas for- } \\
\text { mando os primeiros aminoácidos que, por precipitação, chegaram aos "corpos } \\
\text { de água". Através de combinações de aminoácidos e descargas elétricas surgi- } \\
\text { ram os primeiros seres vivos (coacervados). O acúmulo de nutrientes, de sais } \\
\text { minerais, aminoácidos, peptídeos, etc. que começaram a interagir entre si pos- } \\
\text { sibilitaram o surgimento do ser vivo mais simples, com complexos protéicos } \\
\text { capazes de duplicação e interação com o meio, a aglomeração de U + C e } \\
\text { aglomerados de moléculas que adquiriram a capacidade de reprodução e cres- } \\
\text { cimento. A mistura de substâncias sob determinadas condições de calor e pres- } \\
\text { são permitiu modificações atmosféricas e locais, além dos simbiontes, que ge- } \\
\text { raram o surgimento de organismos capazes de sobreviver e deixar descenden- } \\
\text { tes (teoria evolucionista)." }\end{array}$ \\
\hline
\end{tabular}

discurso se mostrou de fraca adesão no grupo ${ }^{12}$, prevaleceu a ancoragem científica. Ainda assim, merece atenção porque ele se manifestou sem mostrar que há uma distinção entre o discurso científico e o religioso, ou seja, há indícios de conflito entre um e outro.

O discurso Evolução química recorre às explicações derivadas do consenso científico mínimo, já discutidas anteriormente; mas, ao desenvolverem o tema, os licenciandos limitam-se a um sistema conceitual muito restrito. Por exemplo, as atuais formulações sobre o

${ }^{12}$ Número de ocorrências para cada ideia central: Evolução química - 29 alunos; Criação divina - seis alunos; Origem no Big Bang - três alunos; Não respondeu - um. 
assunto admitem que, na Terra, a origem das primeiras moléculas orgânicas simples pode não ter sido única, uma vez que ocorreram diversas catástrofes no momento da formação da mesma ou, mesmo, que a origem de moléculas orgânicas pode ter acontecido em outras partes do universo. Por isso, não se pode afirmar que a evolução química tenha acontecido apenas uma vez. Já os licenciandos explicam-na como uma sucessão de eventos, com apenas um ponto de partida, como pode ser visto no seguinte fragmento de discurso:

"A vida surge espontaneamente em qualquerparte do universo através do aumento da complexidade de estruturas não vivas e a combinação de diversos fatores e eventos químicos, físicos e biológicos, que juntos com as condições ambientais propicias originou a vida. A sucessão de eventos complementares, como o de substâncias quimicas se combinaram e começaram a se organizar e criar complexidade". (Quadro I - DSC 3)

O não reconhecimento de certa diversidade de possibilidades para o processo de origem da vida nos dá um primeiro indício de que o discurso dos licenciandos enquadra a teoria em uma descrição típica de explicações científicas sob condições de fechamento. Sob tais condições é que o cientista costuma observar uma regularidade invariável de eventos e certa simplicidade nas relações de causa e efeito. Ao mesmo tempo, a coerência interna do discurso coletivo levanta o problema da fonte (ou das fontes) dessa narrativa coerente, embora simplificada demais.

É preciso observar também que o discurso dos licenciandos não põe a devida ênfase sobre processos-chave. Nos seres vivos que conhecemos, a replicação de moléculas portadoras de informações genéticas é uma característica universal. Isto leva ao pressuposto de que, durante o processo de origem da vida, houve uma etapa decisiva caracterizada pelo estabelecimento de uma relação de dependência mútua entre ácidos nucléicos e proteínas (estruturais ou enzimáticas). Vale a pena ressaltar que os alunos não deram destaque a esta questão e, também, que ela não está presente nos livros didáticos. Mas, para a comunidade científica, ela é uma questão decisiva, ou seja, entender como os ácidos nucléicos passaram a desempenhar as funções que possuem hoje é tema primordial para o estabelecimento da teoria de origem da vida (PERETÓ, 2005).

O discurso Evolução química também evidenciou sérias deficiências quanto ao conteúdo efetivo dos conhecimentos dos licenciandos. Observe-se, por exemplo, a referência às chuvas como fator de resfriamento do planeta Terra, explicação inepta e que deixa de lado qualquer consideração sobre o processo espontâneo de perda de calor pelo planeta, após a sua separação do Sol; e, também, o papel dessas chuvas, o que é mencionado sem qualquer especificação causal, no surgimento, ou chegada, aos mares, dos gases (possivelmente amônia $\left(\mathrm{NH}_{3}\right)$ e metano $\left(\mathrm{CH}_{4}\right)$ envolvidos na formação dos primeiros aminoácidos:

"Houve chuva que resfriou a superficie da Terra e com ela vieram os gases que foram rearranjados por descargas elétricas e reações químicas formando os primeiros aminoácidos que, por precipitação, chegaram aos "corpos de água". Através de combinações de aminoácidos e descargas elétricas surgiram os primeiros seres vivos (coacervados)”. (Quadro I - DSC 3) 
Em resumo, os licenciandos, no discurso Evolução química, partem da matriz de ideias do consenso científico de que o ambiente que possibilitou a formação dos primeiros seres vivos era radicalmente diferente do que temos hoje, mas restringem-se à ideia clássica proposta por Miller (atmosfera primitiva) e não conhecem outras possibilidades, hipóteses.

É de se notar também que esse discurso, embora apresentado como reconstituição de eventos passados, numa escala temporal e geográfica vastíssima, mostra encadeamentos que mais se parecem com o de um processo restrito, quase elementar; as possibilidades de atividades relevantes por parte de cada componente mostram-se muito limitadas, o que leva a enunciados do tipo "porque A, então B, o que, por sua vez, só podia levar a C". Mais uma vez devemos enfatizar que os estudantes em questão parecem discutir um problema científico da ordem do "aberto" segundo cânones de cientificidade mais adequados à dimensão do "fechado".

Fica claro que o aspecto mais interessante de uma formação científica, ou seja, a delimitação de quais são os problemas a serem resolvidos e quais são os problemas mais importantes, parece também estar ausente nas formulações dos licenciandos. Posto de outro modo: uma sequência de informações obtidas pela atividade dos cientistas, por si só, não constitui uma abordagem científica.

Até aqui enfatizamos o tipo de epistemologia implícita ao discurso dos licenciandos, bem como as suas imprecisões em termos de conteúdo conceitual. Resta identificar a origem mesma desse conteúdo, ou seja, uma explicação da fonte de onde provêm os conceitos que estruturam esse discurso. Isto foi obtido pela comparação com livros didáticos do Ensino Médio $^{13}$, que mostrou uma série de semelhanças com o padrão de explicação contido no discurso Evolução química. Postulamos que este discurso deve estar relacionado com o que os alunos aprenderam no Ensino Médio ${ }^{14}$ e, quando chegam ao final da licenciatura, continuam ligados a ele em suas atividades de ensino.

\footnotetext{
${ }^{13}$ Amabis e Martho (1995); César e Sezar (1995); Linhares e Gewandsznajder (1995); Soares (1995); Lopes (1997); Linhares e Gewandsznajder (1998); Linhares e Gewandsznajder (2000); César e Sezar (2002a); César e Sezar (2002b); Linhares e Gewandsznajder (2003).

${ }^{14}$ Para a explicação da origem da vida, os livros didáticos de Ensino Médio argumentam que, nas atuais condições do planeta, cada ser vivo só surge a partir de outro preexistente, pelos processos de reprodução, assexuada ou sexuada. Este é o ponto que permite perguntar como surgiu o primeiro ser vivo na Terra, e todos os livros explicam a origem da vida pelo que chamamos de evolução química, pela hipótese mais aceita na ciência. Em geral, o ponto de partida é a descrição dos experimentos de Miller. Explica-se que, nesses experimentos, foram misturados gases (moléculas inorgânicas) que se supunha serem os mesmos que formavam a atmosfera primitiva, e esta mistura foi submetida a descargas elétricas, que simulavam as tempestades que ocorriam no período inicial. A explicação é completada dizendo-se que, com esses experimentos, foram produzidos alguns aminoácidos, moléculas orgânicas componentes das proteínas dos organismos atuais. A partir desse experimento, retornam a quatro bilhões de anos, descrevendo, etapa por etapa, o que deve ter ocorrido para que o primeiro ser vivo fosse formado. Podemos resumir essa descrição da seguinte forma: existia uma atmosfera primitiva (moléculas inorgânicas) que se reorganizou a partir das descargas elétricas. Esta reorganização formou moléculas orgânicas simples que caíram no mar com as tempestades. A partir de reações entre as moléculas orgânicas simples, formaram-se moléculas orgânicas mais complexas. Essas primeiras moléculas complexas seriam as proteínas, e novas reações entre as mesmas originaram novas proteínas e, além disso, açúcares, lipídios e ácidos nucléicos. Com isto, teríamos todas as moléculas orgânicas necessárias para o funcionamento de qualquer ser vivo. Destacam ainda que, para a formação do primeiro ser vivo, deve ter ocorrido a compartimentalização dessas moléculas, delimitando um espaço interno em que ocorreriam reações químicas específicas. Por último, quando esses aglomerados de moléculas (chamados de coacervados) duplicaram-se, os primeiros seres vivos surgiram.
} 
Nicolini, L. B.; Falcão, E. B. M.; Faria, F. S.

A ausência de aprofundamento ou, mesmo, de retificação deste conhecimento na graduação pode contribuir para tal situação, pois na universidade pesquisada este tema não está previsto em nenhuma disciplina obrigatória ou eletiva ${ }^{15}$, não há uma diretriz curricular que determine, formalmente, o ensino de origem da vida na graduação. Esta percepção foi confirmada em entrevistas realizadas com professores da instituição com bons conhecimentos sobre a estrutura curricular. Tampouco o assunto é sistematicamente tratado em disciplinas com as quais ele seria compatível (como Biologia Geral, Bioquímica e Biofísica) ${ }^{16}$. Tal ausência foi justificada por este tema não ser considerado fundamental e, portanto, professores poderiam, ou não, incluí-lo em suas aulas. Nas palavras de um desses professores:

"O tema origem da vida era abordado na graduação na década de 1970 por ser um tema que estava na "moda". Com o tempo, saiu de "moda" e, conseqüientemente, foi deixando de ser abordado na graduação e, além disso, é um tema muito especializado e nenbum professor, na nossa instituição, faz pesquisas nesta área". (NICOLINI, 2006)

\section{Considerações finais}

O presente trabalho identificou e analisou a representação social do tema origem da vida de estudantes da licenciatura em Ciências Biológicas. O interesse surgiu a partir dos relatos de dificuldades de ensinar tal conteúdo no Ensino Básico; de que existem lacunas nas hipóteses explicativas da ciência sobre este fenômeno. Sendo assim, ocorreu a indagação de quais seriam os elementos formadores das concepções deste tema entre os futuros professores de ciências e biologia, e o caminho escolhido foi buscar a representação social de origem da vida destes licenciandos.

De maneira geral, podemos dizer que a representação social de origem da vida expressa pelos licenciandos foi fortemente marcada, ou ancorada, pelo fundo de ideias consensuais da comunidade científica, tal como caracterizada na introdução do presente trabalho. Porém, a exposição dessas ideias foi feita com evidentes imprecisões, que vão desde "o resfriamento da superfície da Terra pelas chuvas" até o enunciado ambíguo sobre a relação entre chuva, atmosfera e primeiras moléculas orgânicas. A essas devemos acrescentar o discurso Origem no Big Bang, que lança mão de uma teoria sobre a origem do universo para responder a uma pergunta sobre origem da vida, ressalvando que esse discurso, expresso por três sujeitos, foi o de menor adesão no grupo estudado.

Em que pese a relevância das imprecisões e erros acima comentados, o que nos chamou particularmente a atenção, no discurso Evolução química, foi a ausência de referên-

\footnotetext{
${ }^{15}$ Pesquisa realizada em documentos oficiais da universidade em questão.

${ }^{16}$ Em certos cursos, como Evolução, o assunto pode ser, ou não, apresentado, dependendo do professor encarregado do curso. De qualquer maneira, trata-se, no máximo, de um assunto tratado de forma mais ou menos sumária.
} 
Origem da vida: como licenciandos ...

cias a teorizações conflitantes, ou a hipóteses alternativas quanto a processos e fatores relevantes, segundo o julgamento atual da comunidade científica. Seria bom esclarecer que, por "cenários" alternativos, entendemos diferenças no enquadramento espaço-temporal mais geral da teorização: outros corpos celestes, em oposição a, por exemplo, oceano primitivo do planeta Terra. E, mesmo nesse último caso, ainda há possibilidades alternativas a serem consideradas, como entre fontes termais no leito oceânico ou lagunas e poças costeiras. No caso do termo "processos", queremos nos referir, por exemplo, a diferentes possibilidades sobre as condições iniciais de concentração de moléculas orgânicas simples (interação com argilas ou com pirita). Nunca é demais enfatizar que esses meandros do estudo da origem da vida não são um quadro ultra-atualizado ou recentíssimo desse campo científico, mas sim um conjunto de possibilidades que há bom tempo vem ocupando cientistas do mundo inteiro.

Outro ponto que cabe comentar é que seria injustificado concluir, diretamente desses resultados, qual a relevância da influência religiosa para a formação das ideias sobre origem da vida, entre os licenciandos. Por um lado, os seis casos de discurso religioso (em um total de 39) por nós identificados configuram um grau nada desprezível de influência; por outro lado, esse número, por si só, poderia nos levar a uma subestimação da influência total da perspectiva religiosa. Isto porque não podemos excluir a possibilidade de que (a) a adoção simultânea de fundamentos científicos e religiosos seja generalizada, mas que (b) as respostas a perguntas de uma pesquisa acadêmica, sobre a formação dos próprios licenciandos, pode ter influenciado as respostas, no sentido de se focalizarem nos aspectos limitados às suas próprias experiências acadêmicas ${ }^{17}$.

Seria importante que os professores de biologia pudessem ter acesso, de forma mais completa, aos aspectos teóricos sobre origem da vida, e fossem mais esclarecidos quanto à natureza da produção do conhecimento científico, isto é, que o conhecimento é construído a partir de hipóteses, testes, controles, perguntas e tentativas de produzir respostas, com debates auxiliando esta construção. Ambos, domínio do conteúdo básico das teorias de origem da vida e clareza quanto à natureza da ciência, poderão gerar uma postura correta no encaminhamento pedagógico deste tema e das possíveis dificuldades com as representações que seus alunos muitas vezes, solidamente, trazem às salas de aula - conforme mostram inúmeros estudos no campo do ensino das ciências, assentados numa concepção de conhecimento como algo humano e social, dependente dos modos de ver e de praticar as ciências na sala de aula, entre outros.

${ }^{17}$ Outras pesquisas realizadas nesta instituição (FALCÃO, SANTOS E RAGGIO, 2008) revelaram a presença de crenças religiosas na grande maioria dos discentes, o que reforça os dados da pesquisa aqui relatada. 
Nicolini, L. B.; Falcão, E. B. M.; Faria, F. S.

\section{Referências}

AMABIS, J. M.; MARTHO, G. R. Biologia das células. São Paulo: Moderna, 1995.

; _ B B Biologia das células. São Paulo: Moderna, 2004.

BHASKAR, R. A realist Theory of Science. London: Verso, 1975.

BIZZO, N.; MOLINA, A. El mito darwinista em el aula de clase: um análisis de fuentes de información al gran público. Ciência e Educação, Bauru, v. 10, n. 3, p. 401-416, 2004.

BRASIL. Ministério da Educação, Secretaria de Educação Básica. Parâmetros

Curriculares Nacionais para o Ensino Médio (PCNEM) - Ciências da natureza, matemática e suas tecnologias. Brasília: MEC, 2006.

CÉSAR, S. J.; SEZAR, S. Biologia 1. São Paulo: Saraiva, 1995.

.; B__ Biologia 1. São Paulo: Saraiva, 2002a.

;_ B_ Biologia. São Paulo: Saraiva, 2002b. (volume único)

DAMINELI, A.; DAMINELI, D. S. C. Origens da vida. Estudos Avançados, São Paulo, v. 21, n. 59, p. 263-284, 2007.

FALCÃO, E. B. M.; SANTOS, A. G.; RAGGIO, R. Conhecendo o mundo social dos estudantes: encontrando a ciência e a religião. Revista Eletrónica de Enseñanza de las Ciencias, v. 7, n. 2 p. 420-438, 2008. Disponível em: <http://www.saum.uvigo.es/reec>. Acesso em: 8 abr. 2010.

KAWASAKI, C. S.; EL-HANI, C. N. Uma análise das definições de vida encontradas em livros didáticos do Ensino Médio. In: ENCONTRO PERSPECTIVAS DO ENSINO DE BIOLOGIA, 8., 2002, São Paulo. Anais... São Paulo: USP, 2002. Disponível em: <http:// www.gphfecb.ufba.br/Portugues/Textos/Kawasaki1.pdf>. Acesso em: 8 abr. 2010.

LEFÈVRE, F.; LEFÈVRE A. M. C. Princípios básicos e conceitos fundamentais do Discurso do Sujeito Coletivo. In: . (Orgs.). O Discurso do Sujeito

Coletivo: um novo enfoque em pesquisa qualitativa (desdobramentos). Caxias do Sul: EDUSC, 2003. p. 13-57.

LINHARES, S.; GEWANDSZNAJDER, F. Biologia hoje. São Paulo: Ática, 1995. v. 1.

.; B__ Biologia hoje. São Paulo: Ática, 1998. v. 1.

.; ___ Biologia: programa completo. São Paulo: Ática, 2000.

;____ Biologia. São Paulo: Ática, 2003. (volume único)

LOPES, S. Bio. São Paulo: Saraiva, 1997. v. 1.

MOSCOVICI, S. Representações sociais: investigações em Psicologia Social. Petrópolis: Vozes, 2003. 
Origem da vida: como licenciandos ...

NICOLINI, L. B. Origem da vida: como os licenciandos em Ciências Biológicas lidam com este tema? 2006. 97f. Dissertação (Mestrado em Tecnologia Educacional) - Núcleo de Tecnologia Educacional para a Saúde, Universidade Federal do Rio de Janeiro, Rio de Janeiro, 2006.

PERETÓ, J. Controversies on the origin of life. International Microbiology, Madrid, v. 8, n.1, p. 23-31, 2005. Disponível em: <http://www.scielo.isciii.es>. Acesso em: 18 jun. 2008.

SCHEID, N. M. J.; FERRARI, N.; DELIZOICOV, D. A construção coletiva do conhecimento científico sobre a estrutura do DNA. Ciência e Educação, Bauru, v. 11, n. 2, p. 223-233, 2005.

SOARES, J. L. Biologia. São Paulo: Scipione, 1995. v. 1.

VIEYRA, A.; SOUZA-BARROS, F. Teorias da origem da vida no século XX. In: ELHANI, C. N.; VIDEIRA, A. A. P. (Orgs.). O que é vida? Para entender a Biologia do Século XXI. Rio de Janeiro: Faperj/Relume Dumará, 2000. p. 71-101.

ZAIA, D. A. M. Da geração espontânea à química prebiótica. Química Nova, São Paulo, v. 26, n. 2, p. 260-264, 2003. 